\title{
Characterization of Tail Sheath Protein of N4-Like Phage phiAxp-3
}

\begin{abstract}
Zheng Zhangit, Changyu Tian't, Jiangtao Zhao ${ }^{3}$, Xiao Chen ${ }^{1}$, Xiao Wei ${ }^{2}$, Huan $\mathrm{Li}^{2}$, Weishi Lin ${ }^{2}$, Ruo Feng ${ }^{3}$, Aimin Jiang ${ }^{1}$, Wenhui Yang ${ }^{4 *}$, Jing Yuan ${ }^{2 *}$ and Xiangna Zhao ${ }^{2 *}$

${ }^{1}$ College of Food Science, South China Agricultural University, Guangzhou, China, ${ }^{2}$ Institute of Disease Control and Prevention, China PLA, Beijing, China, ${ }^{3}$ Department of Histology and Embryology, School of Basic Medical Sciences, Zhengzhou University, Zhengzhou, China, ${ }^{4}$ State Key Laboratory of Pathogen and Biosecurity, Beijing Institute of Microbiology and Epidemiology, Beijing, China
\end{abstract}

Achromobacter phage phiAxp-3, an N4-like bacteriophage, specifically recognize Achromobacter xylosoxidans lipopolysaccharide (LPS) as its receptor. PhiAxp-3 tail sheath protein (TSP, ORF69) shares 54\% amino acid sequence identity with the TSP of phage N4 (gp65); the latter functions as a receptor binding protein and interacts with the outer membrane receptor NfrA of its host bacterium. Thus, we hypothesized that ORF69 is the receptor-binding protein of phiAxp-3. In the present study, a series of ORF69 truncation variants was constructed to identify the part(s) of this protein essential for binding to $A$. xylosoxidans LPS. Phage adsorption and enzyme-linked immunosorbent assay showed that amino acids 795-1195 of the TSP, i.e., ORF69(795-1195), are sufficient and essential for receptor and binding. The optimum temperature and $\mathrm{pH}$ for the functions of ORF69 and ORF69(795-1195) are 4/25 $\mathrm{C}$ and 7, respectively. In vitro cytotoxicity assays showed that ORF69 and ORF69(795-1195) were respectively toxic and non-toxic to a human immortalized normal hepatocyte cell line (LO2; doses: 0.375-12 $\mu \mathrm{g}$ ). The potential of this non-toxic truncated version of phiASP-3 TSP for clinical applications is discussed.

Keywords: Achromobacter xylosoxidans A22732, tail sheath protein, phage adsorption assay, enzyme-linked immunosorbent assay (ELISA), characterization

\section{INTRODUCTION}

Given their rapid proliferation and high specificity, phages are extensively used in several applications, including rapid detection of pathogenic bacteria (Schofield and Westwater, 2009), assessment of water quality and sewage treatment efficiency (Durán et al., 2002), and classification and identification of bacterial species (Richter et al., 2017). These applications of phages are generally based on the premise that the tail protein can identify receptors on the bacterial surface. Moreover, phage-based disease treatments have attracted recent research attention because of increasing concerns with drug resistance in bacteria (Park and Myung, 2014; Hodyra-stefaniak et al., 2015; Reardon, 2017). The tail protein of phages is significant for the interaction between bacteriophages and host bacteria, and this interaction is a research topic with considerable potential. Singh et al. (2010) have shown the application of genetically engineered bacteriophage tail proteins as molecular probes for the sensitive and selective detection of Salmonella enterica. Miernikiewicz et al. (2016) used the tail protein gp12 of T4 phage in vivo in rice to counteract lipopolysaccharide (LPS)-induced inflammation. 
Recognition of and connection with host cells are important steps for all phages to infect bacterial cells. In general, phages can only be stably adsorbed onto the host bacterial surface by identifying an exposed structure on the cell surface as the recognition receptor and then injecting their genetic materials into the cytoplasm of the host bacteria (Krüger and Schroeder, 1981; São-José et al., 2004). Porins, affinity transporters, and LPS are the most common outer membrane components that act as receptors for tailed phages that infect Gram-negative bacterium (Lindberg, 1973; São-josé et al., 2006). N4 phage is one type of phage that infects the Gram-negative bacterium Escherichia coli. The protein gp65, which constitutes a sheath surrounding the tail tube of N4 phage (Choi et al., 2008), is adsorbed onto the cell surface by recognition of the outer membrane protein NfrA (Kiino and Rothmandenes, 1989; Kiino et al., 1993; Mcpartland and Rothman-Denes, 2009). Mcpartland and Rothman-Denes (2009) speculated that direct interaction of NfrA with gp65 is responsible for the initial signaling event leading to N4 DNA and vRNAP injection. Achromobacter xylosoxidans A22732 is a Gram-negative bacterium that was isolated from a Chinese patient with pneumonia and is resistant to multiple $\beta$-lactam antibiotics, including carbapenems. This dangerous opportunistic pathogen is distributed in the water environment (Sader and Jones, 2005; Chen et al., 2014). Previous research identified the N4-like phage phiAxp-3 in hospital wastewater. This phage specifically recognizes and pyrolyzes A. xylosoxidans A22732 and therefore has potential for phage therapy. The genome of phiAxp-3 has been fully sequenced and annotated to determine whether there were any potentially "undesirable" genes (e.g., virulent and/or toxic genes) present (Ma et al., 2016). The absence of these "undesirable" genes has important safety implications (Soffer et al., 2017). No toxin, virulence, repressor genes, integrases, recombinases nor any bacterial gene were detected (Ma et al., 2016). The genome analyses in previous study provide no evidence of any potentially dangerous transducing ability of this lytic phage, supporting the potential of the phage for biocontrol applications (Ma et al., 2016). Experimental results on receptor identification showed that the receptor of phiAxp-3 is LPS (Ma et al., 2016). LPS can trigger inflammatory responses in humans and animals. Analysis of the interactions between the tail proteins of phages and the LPS receptor can be used to develop potential drugs for clinical treatment (Miernikiewicz et al., 2016).

In this study, tail sheath protein (TSP) sequences of phiAxp3 were screened bioinformatically, and a region with the same effect as the full-length TSP of the phage was identified by protein truncation experiments. The characteristics of the truncated protein, including toxicity, were investigated. The results of this study offer theoretical foundations for future applications of the TSP of N4-like phages.

\section{MATERIALS AND METHODS}

\section{Bacterial Strains, Phages, Plasmids, and Media}

Achromobacter xylosoxidans A22732 and phiAxp-3 were stored in our laboratory and cultured at $37^{\circ}$ C. E. coli DH5 $\alpha$, E. coli BL21
( $\lambda$ DE3) competent cells and protein expression plasmid pET28a were purchased from Beijing BIOMED, Co., Ltd. Luria-Bertani (LB) medium was used for bacterial liquid cultures, and soft-agar medium included an additional $0.7 \%$ (wt./vol.) agar.

\section{Cloning of TSP Genes of phiAxp-3}

A $25 \mu \mathrm{L}$ polymerase chain reaction (PCR) system was established by using phiAxp-3 genomic DNA. Table 1 lists the primers used. PCR products were recycled using the QIAquick Gel Extraction Kit. NheI and BamHI double enzyme digestion was performed on PCR products and carrier plasmids. DNA fragments were ligated overnight at $4^{\circ} \mathrm{C}$ and the target segments of the TSP gene were cloned into pET28a.

\section{Expression and Purification of phiAxp-3 TSP Variants}

pET28a containing cloned TSP genes from phiAxp-3 was transformed into $E$. coli BL21 ( $\lambda$ DE3) cells and then cultured in high-salinity liquid $\mathrm{LB}$ medium $(10 \mathrm{~g} / \mathrm{L}$ of $\mathrm{NaCl})$ supplemented with $0.1 \%$ ampicillin $\left(37^{\circ} \mathrm{C}, 180 \mathrm{rpm}\right)$. When the $\mathrm{OD}_{600} \mathrm{~nm}$ reached 0.8 , IPTG solution (Table 1 ) was added and then cell was cultured overnight $\left(25^{\circ} \mathrm{C}, 100 \mathrm{rpm}\right)$.

Bacteria were collected by centrifugation and washed three times with by $0.5 \times$ phosphate-buffered saline (PBS). After resuspension in $15 \mathrm{~mL}$ lysis buffer, the bacteria were treated by $30 \%$ ultrasonic power (Sonics VCX750, United States) to break the cells (2 s on/4 s off) for $10 \mathrm{~min}$. Then, $20 \mu \mathrm{L}$ of RNase and DNase were added at room temperature for $1 \mathrm{~h}$, and then mixture was centrifuged at $10,000 \mathrm{~g} / \mathrm{min}$ for $40 \mathrm{~min}$ at $4^{\circ} \mathrm{C}$. The supernatant was collected and purified using a Histagged-protein Purification Kit (Beijing CWBIO Company) by following the manufacturer's instructions. Proteins before and after purification were analyzed by SDS-PAGE. The purified proteins were quantified with a Protein Quantification Kit (Beijing BIOMED Company).

\section{Blockage of Phage Adsorption by Purified TSP Variants}

Fresh A. xylosoxidans A22732 solution $\left(50 \mu \mathrm{L}, \mathrm{OD}_{600 \mathrm{~nm}}=3.0\right)$ and $150 \mu \mathrm{g} / \mathrm{mL}$ TSP variants solution $(50 \mu \mathrm{L})$ were mixed at $180 \mathrm{rpm}$ for $10 \mathrm{~min}$ at $25^{\circ} \mathrm{C}$. Then, $100 \mu \mathrm{L}$ of $10^{3}$ plaque-forming units $(\mathrm{PFU}) / \mathrm{mL}$ phage were added and mixed at $16,000 \mathrm{rpm}$ for $3 \mathrm{~min}$ at $4^{\circ} \mathrm{C}$. The phage titer in the supernatant (residual PFU) was determined by counting the bacteriophage plaques on A. xylosoxidans A22732. Addition of $100 \mu \mathrm{L} 1 \times$ PBS (instead of TSP) was used as the negative control, and addition of $100 \mu \mathrm{L} 10^{3}$ $\mathrm{PFU} / \mathrm{mL}$ phage was used as the positive control. The phage titer of the positive control was defined as 100\% (Kiljunen et al., 2011). The titer was determined using tested phage suspension and agar overlay technique (Carlson, 2005). Each index was tested three times.

\section{Lipopolysaccharide Extraction}

Fresh A. xylosoxidans A22732 solution grown overnight at $37^{\circ} \mathrm{C}$ was centrifuged at $8000 \mathrm{~g} / \mathrm{min}$ for $2 \mathrm{~min}$ at $4^{\circ} \mathrm{C}$, cells were killed with $0.5 \%$ phenol, and the mixture was centrifuged again 
TABLE 1 | Relevant information on clones produced and investigated in this work.

\begin{tabular}{|c|c|c|c|}
\hline Protein expression & Primer F (Nhel)/R (BamHI) & Location (bp) & $\begin{array}{l}\text { Additive amount } \\
\text { of IPTG (mM/L) }\end{array}$ \\
\hline ORF69 & CTAGCTAGCATGTCCATCGATGATTATCG/ CGCGGATCCTTATTCCGGCACAGCCGTAGC & $1-4188$ & 1.0 \\
\hline ORF69(595-1395) & CTAGCTAGCGAGGAAGGATGGGGCTGG/ CGCGGATCCTTATTCCGGCACAGCCGTAGC & $1786-4188$ & 1.0 \\
\hline ORF69(795-1395) & CTAGCTAGCGTTGGTTCCAGCCCTGTAA CGCGGATCCTTATTCCGGCACAGCCGTAGC & $2386-4188$ & 0.6 \\
\hline ORF69(995-1395) & CTAGCTAGCCCGCCTACGGGTGTG/ CGCGGATCCTTATTCCGGCACAGCCGTAGC & $2986-4188$ & 0.6 \\
\hline ORF69(1195-1395) & CTAGCTAGCAACCCCATGGATGACAT/ CGCGGATCCTTATTCCGGCACAGCCGTAGC & $3586-4188$ & 0.8 \\
\hline ORF69(795-1195) & CTAGCTAGCGTTGGTTCCAGCCCTGTAA CGCGGATCCCTACTCAGGAGGAATCGGTTC & 2386-3585 & 0.8 \\
\hline ORF69(795-1095) & CTAGCTAGCGTTGGTTCCAGCCCTGTAA CGCGGATCCTTAGACCAGATGCTTACCCGTCAC & 2386-3285 & 0.4 \\
\hline
\end{tabular}

Underlining indicates endonuclease restriction sites.

at $39000 \mathrm{rpm}$. The bacterial pellet was washed three times with distilled water, lyophilized, treated with $90 \%$ phenol/water (1:1), and heated to $65^{\circ} \mathrm{C}$. A. xylosoxidans A22732 LPS was extracted for $15 \mathrm{~min}$ according to previously published methods (Westphal, 1965). The extract was cooled to $4^{\circ} \mathrm{C}$, centrifuged at $5000 \mathrm{~g} / \mathrm{min}$ for $30 \mathrm{~min}$, and the aqueous phase was collected. Distilled water was added to the remaining phenol phase and the extraction process was repeated. LPS was purified according to the method of Simin et al. (2011). DNase $(20 \mu \mathrm{g} / \mathrm{mL})$ and RNase $(40 \mu \mathrm{g} / \mathrm{mL})$ were added to the extraction and tubes were kept at $37^{\circ} \mathrm{C}$ for $4 \mathrm{~h}$. Proteinase $\mathrm{K}(100 \mu \mathrm{g} / \mathrm{mL})$ was added to the tubes at $65^{\circ} \mathrm{C}$ for $1 \mathrm{~h}$, and then they were heated at $100^{\circ} \mathrm{C}$ for $10 \mathrm{~min}$. The tubes were centrifuged at $8500 \mathrm{~g} / \mathrm{min}$ for $15 \mathrm{~min}$. Supernatants were transferred to $15-\mathrm{mL}$ centrifuge tubes, and two volumes of acetone were added to the extracts. Samples were stored at $4^{\circ} \mathrm{C}$ overnight to precipitate LPS. The samples were then centrifuged at $2000 \mathrm{~g} / \mathrm{min}$ for $10 \mathrm{~min}$ at $4^{\circ} \mathrm{C}$, and the precipitates were resuspended in $1 \mathrm{~mL}$ distilled water. Extensive dialysis against double distilled water at $4^{\circ} \mathrm{C}$ was performed until residual phenol was eliminated. Finally, the purified A. xylosoxidans A22732 LPS was lyophilized, weighed, and stored at $4^{\circ} \mathrm{C}$.

\section{Enzyme-Linked Immunosorbent Assay (ELISA) Verification of the Interaction Between LPS and phiAxp-3 TSP Variants}

The interaction between A. xylosoxidans A22732 LPS and TSP variants of phiAxp-3 was tested by ELISA (Martínez-Sernández and Ubeira, 2014). A. xylosoxidans LPS was diluted to $100 \mathrm{ng} / \mathrm{mL}$ with buffer containing (per L) $1.6 \mathrm{~g} \quad \mathrm{Na}_{2} \mathrm{CO}_{3}$ and $2.9 \mathrm{~g}$ $\mathrm{NaHCO}_{3}$. Then, $100 \mu \mathrm{L}$ of LPS solution was immobilized on an ELISA plate and incubated at $37^{\circ} \mathrm{C}$ for $2 \mathrm{~h}$. The mixture was rinsed with PBS-TW2 (PBS solution with 0.05\% Tween 20). Bovine serum albumin (BSA) diluted in PBS-TW2 was then added at a final concentration of $0.1 \%$ and the mixture was left overnight at $4^{\circ} \mathrm{C}$. The wells were then rinsed twice with PBS-TW2. E. coli 0111:B4 LPS was used as a negative control. Different concentrations of His-tagged proteins $(1 \mu \mathrm{g} / \mathrm{mL}-$ $0.12207 \mathrm{pg} / \mathrm{mL})$ were added $(100 \mu \mathrm{L} /$ well $)$ and the plates were incubated for $30 \mathrm{~min}$ at $37^{\circ} \mathrm{C}$. The unrelated protein His-tagged fucosidase (from Bifidobacterium longum XY01) was used as a negative control. The plate was washed five times with PBS-TW2. In this step, proteins that could not bind to LPS were removed. HRP-conjugated anti-6× His antibody (diluted
$1 / 1,000$ in PBS-TW2) was added (100 $\mu \mathrm{L} /$ well) and incubated for $20 \mathrm{~min}$ at $37^{\circ} \mathrm{C}$. The plate was washed again with PBS-TW2 and incubated for $10 \mathrm{~min}$ at room temperature with $50 \mu \mathrm{L} /$ well SigmaFast OPD substrate before the reaction was stopped by addition of $50 \mu \mathrm{L}$ of $3 \mathrm{M} \mathrm{H}_{2} \mathrm{SO}_{4}$. The optical density (OD) was measured at $450 \mathrm{~nm}$, and each index was measured three times.

\section{Effects of Different pH Values and Temperatures on the TSP of phiAxp-3}

To explore the effects of $\mathrm{pH}$ on the TSP, $\mathrm{HCl} / \mathrm{NaOH}$ were added to PBS buffer to adjust the pH between 4 and 10 . TSP variants were pretreated for $10 \mathrm{~min}$ at different $\mathrm{pHs}$ and different temperatures $\left(4-70^{\circ} \mathrm{C}\right.$, in a water bath). Then, the phage adsorption blockage assay was performed to examine the functionality of the treated TSP.

\section{In Vitro Cell Toxicity of the phiAxp-3 TSP}

The toxicity of the TSP of phiAxp-3 (and variants) was tested using normal human liver cells (LO2; American Type Culture Collection). LO2 cells were cultured in high-glucose complete Dulbecco's modified Eagle's medium containing 10\% fetal calf serum, $1 \%$ penicillin $(100 \mathrm{U} / \mathrm{mL})$, and streptomycin $(100 \mathrm{mg} / \mathrm{mL})$ at $37^{\circ} \mathrm{C}$ in $5 \%$ a $\mathrm{CO}_{2}$ atmosphere. Subculture was performed every 4 days (until the cell fusion rate reached $80 \%$ ). One hundred $\mu \mathrm{L}$ of protein solution diluted in DPBS was added in the following amounts: $12,6,3,1.5,0.75$, or $0.375 \mu \mathrm{g}$. In the control group, $100 \mu \mathrm{L}$ DPBS were added. The survival rate of LO2 cells was tested using the 3-(4,5)-dimethylthiahiazo (-z-y1)-3,5di- phenytetrazoliumromide (MTT) method after $24 \mathrm{~h}$ of culture (Gerlier and Thomasset, 1986). Each index was measured three times.

\section{Accession Number of Nucleotide Sequence}

The amino acid sequence of the TSP of phiAxp-3 was obtained from the NCBI database (accession number ALA45538.1). The accession number of the amino acid sequence of N4 phage gp65 in NCBI is YP_950543.

\section{Statistical Analyses}

Nucleotide sequences were compared using DNAMAN software 8.0 (Lynnonon Biosoft, Quebec City, QC, Canada). The mean values of triplicate experimental readings were determined and 


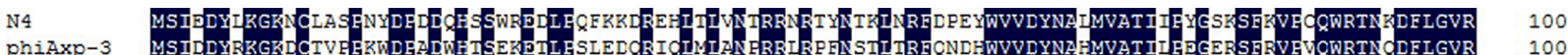

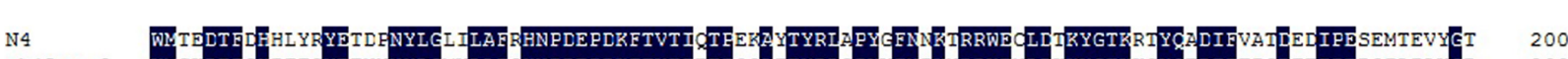

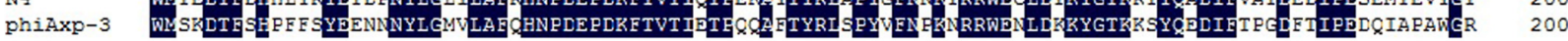

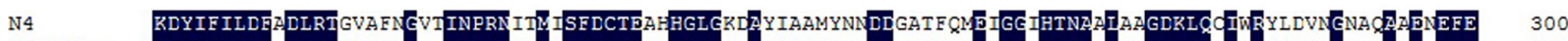

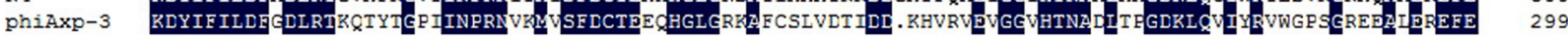

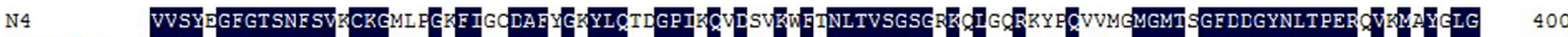

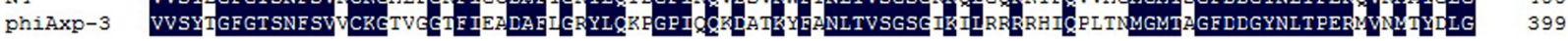

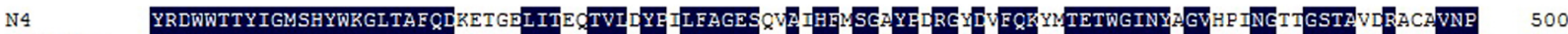

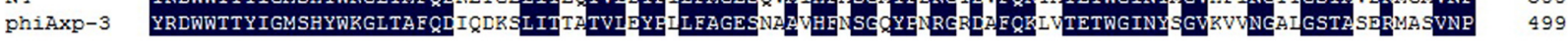

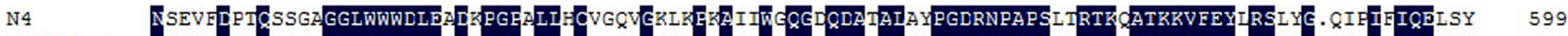

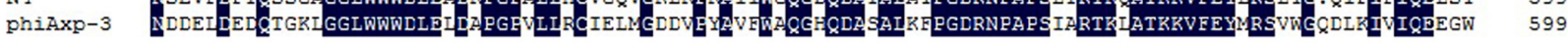

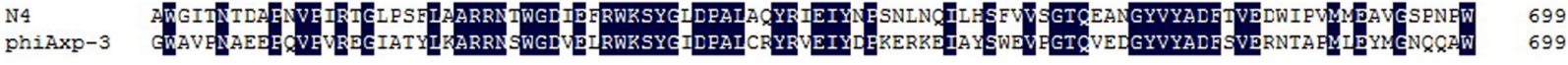

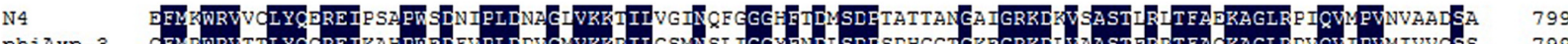

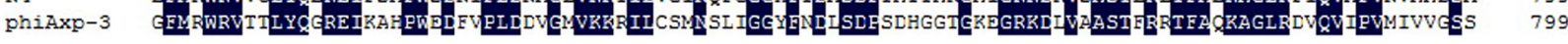

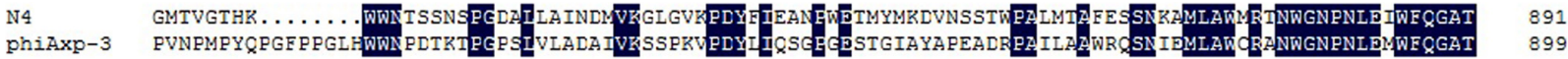

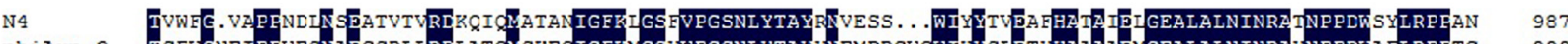

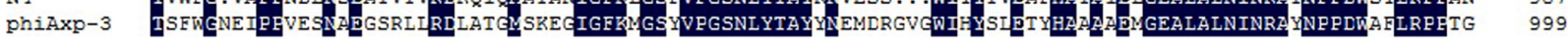

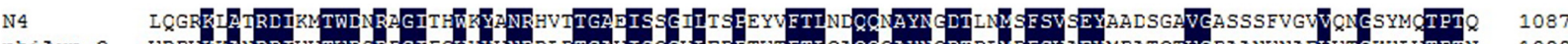

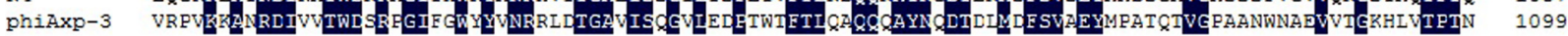

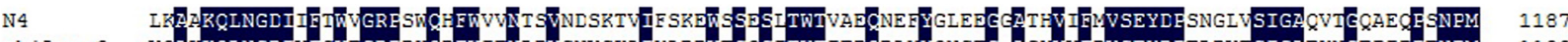

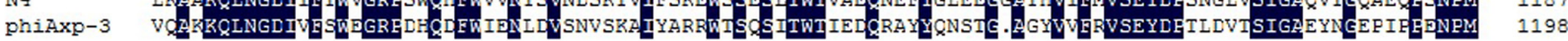

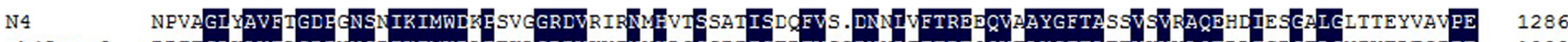

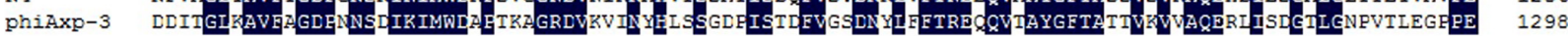

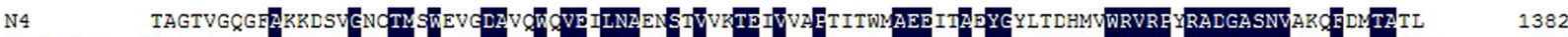

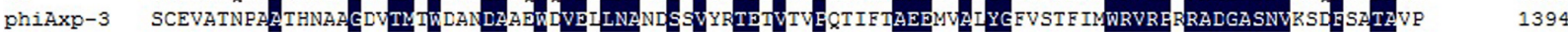

FIGURE 1 | Sequence alignment of the tail proteins (TSP) of phages phiAxp-3 and N4. Identical residues are shaded in black. Gaps (indicated by dotted lines) were introduced into the sequences to maximize the alignment. Numbering is from the N-terminal methionine. Multiple sequence alignment was analyzed and edited with DNAMAN software.

subjected to ANOVA. The means were separated using Duncan's multiple range test with the aid of SPSS version 19.0 (SPSS, Inc., United States).

\section{RESULTS}

\section{Expression and Purification of TSP and Variants of phiAxp-3}

The TSP of phiAxp-3 was predicted to be the 69th open reading frame (ORF), a 1395 amino acid protein which shares $54 \%$ identity with the amino acid sequence of gp65 of the N4 phage (Figure 1). To analyze the location(s) of the receptor-binding region of the TSP, $E$. coli BL21 $(\lambda \mathrm{DE} 3)$ cells were transformed with pET28a expression plasmids that expressed His-tagged full-length ORF69, ORF69(595-1395), ORF69(795-1395), ORF69(995-1395), ORF69(1195-1395), ORF69(795-1195), or ORF69(795-1095) (Figures 2A,B). In this notation, for example, ORF69(595-1395) represents amino acids 595 to 1395 of the phiAxp-3 TSP of ORF69. These proteins were then purified by $\mathrm{Ni}$-affinity chromatography with the expected sizes: $154,88,66,44,22,44$, and $33 \mathrm{kDa}$, respectively (Figure 2C).

\section{Blockage of phiAxp-3 Adsorption by Purified TSP and Variants}

We hypothesized that the TSP of phiAxp-3 plays a role in receptor recognition. Therefore, it was necessary to test whether 


\section{A}

ORF69

ORF69(595-1395)

ORF69(795-1395)

ORF69(995-1395)

ORF69(1195-1395)

ORF69(795-1195)

ORF69(795-1095)
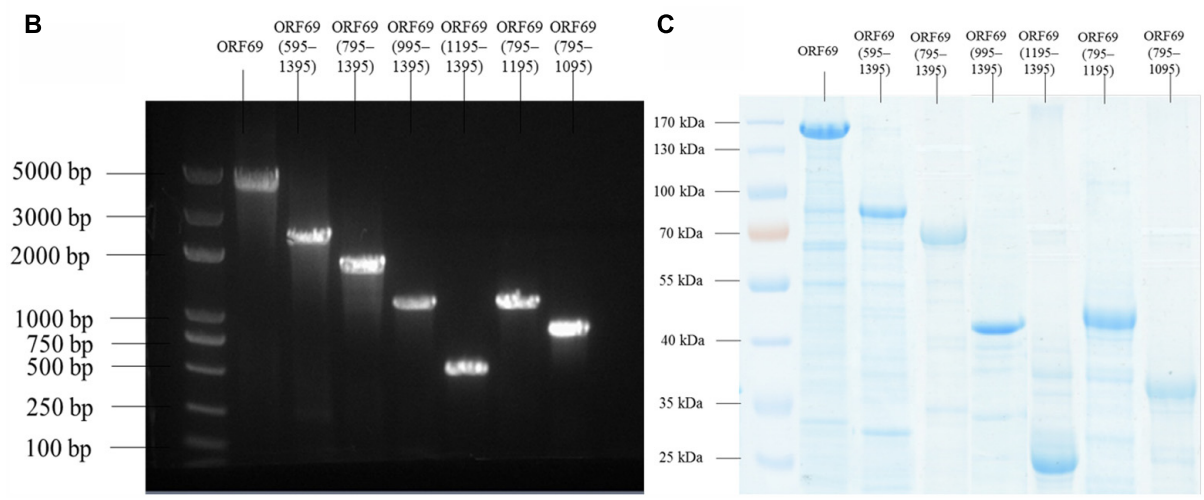

FIGURE 2 | (A) Positions of the fragments of the phiAxp-3 TSP studied in this work. The thick lines represent the fragments construced/tested, and the numbers denote the starting and ending amino acid positions. (B) Seven fragments spanning different portions of the TSP were expressed as His6-tagged fusion proteins: ORF69(full-length), ORF69(595-1395), ORF69(795-1395), ORF69(995-1395), ORF69(1195-1395), ORF69(795-1195), and ORF69(795-1095). (C) SDS-PAGE showing the purified TSP variants with molecular masses ranging from 22 to $154 \mathrm{kDa}$.

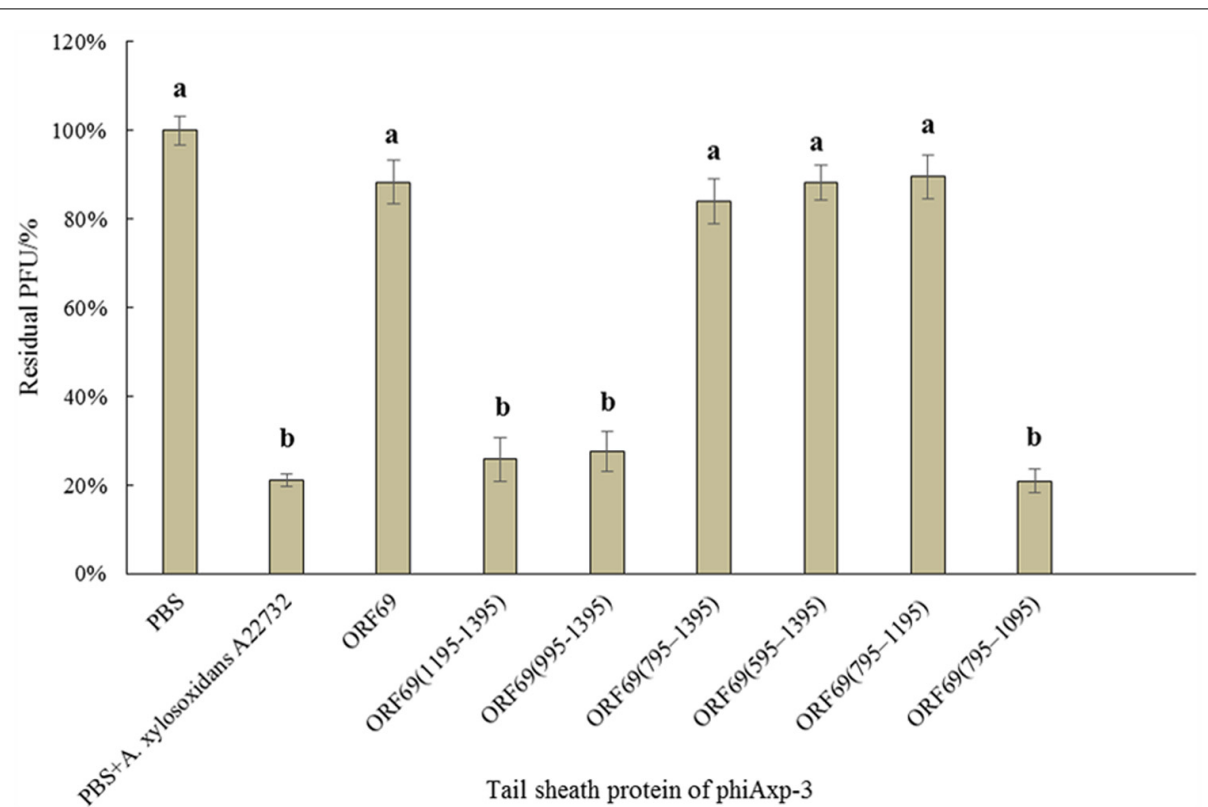

FIGURE 3 | Effects of purified TSP and truncations on phiAxp-3 adsorption to the host bacterium Achromobacter xylosoxidans A22732. Numerical values represent the mean of three parallel test results and different letters represent significant differences between data $(P<0.05)$.

the purified TSP and truncations could inhibit phiAxp-3 binding to the host bacterium. The purified proteins were mixed with fresh A. xylosoxidans A22732 solution and the plaquing efficiency of phiAxp-3 was measured. TSP, variants
ORF69 (i.e., the full-length protein), ORF69(595-1395), ORF69(795-1395), and ORF69(795-1195) could compete with phage phiAxp-3 for adsorption to the host bacteria, thereby inhibiting phage adsorption (Figure 3), but the other 


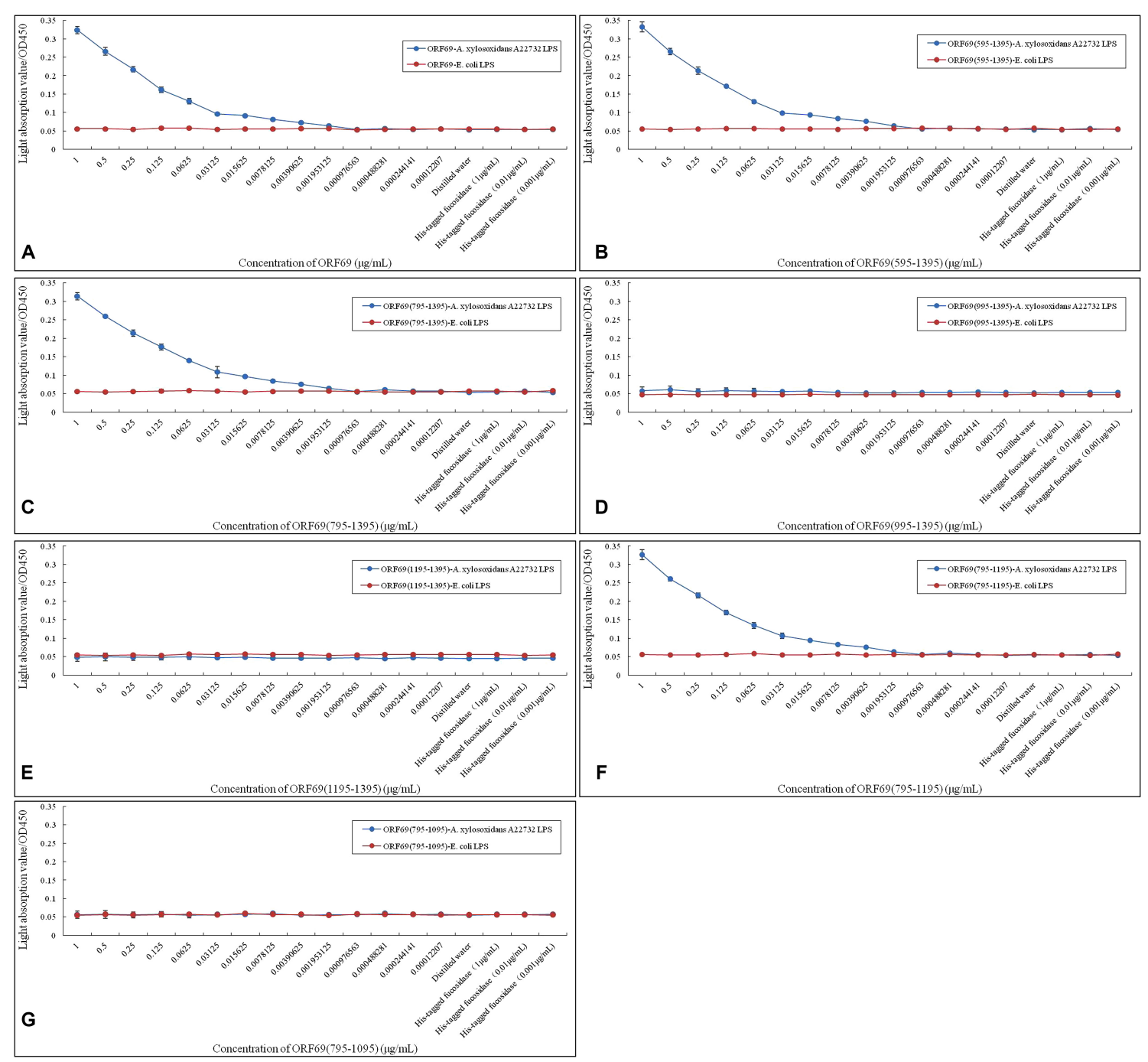

FIGURE 4 | Enzyme-linked immunosorbent assay assessing A. xylosoxidans lipopolysaccharide (LPS) interaction with phiAxp-3 TSP and variants. (A-G) Represent the A. xylosoxidans LPS interaction with ORF69, ORF69(595-1395), ORF69(795-1395), ORF69(995-1395), ORF69(1195-1395), ORF69(795-1195),

ORF69(795-1095), respectively.

TSP truncations ORF69(995-1395), ORF69(1195-1395) and ORF69(795-1095), could not $(P<0.05)$. The adsorption assay demonstrated that TSP functions as a receptor-binding protein, and that residues 795 to 1195 of TSP were sufficient to inhibit phiAxp-3 binding to the receptor in vitro.

\section{Binding of TSP and Variants to \\ A. xylosoxidans LPS in Vitro}

A previous report demonstrated that LPS is the adsorption target (receptor) of phage phiAxp-3 (Ma et al., 2016). The specific interaction of LPS purified from A. xylosoxidans with purified TSP and its variants was confirmed by ELISA (Figure 4). ORF69(595-1395) (Figure 4B), ORF69(795-1395) (Figure 4C) and ORF69(795-1195) (Figure 4F), like the ORF69 (Figure 4A), interacted specifically with A. xylosoxidans LPS and the results revealed a direct correlation between the concentration of each of these TSP variants and the OD in the ELISA. The other three proteins, ORF69(995-1395) (Figure 4D), ORF69(1195-1395) (Figure 4E) and ORF69(795-1095) (Figure 4G), did not interact with A. xylosoxidans LPS. Therefore, consistent with the results of the phage adsorption assay (Figure 3), residues 795 to 1195 of the TSP are the key region for binding to the receptor, i.e., A. xylosoxidans LPS.

\section{Effects of Different pHs and Temperatures on the TSP of phiAxp-3}

Stability studies of ORF69 and ORF69(795-1195) were conducted at different $\mathrm{pH}$ and temperature values. Figure 5 summarizes the results. The optimum $\mathrm{pH}$ for the protein function (i.e., binding to the host bacterium) was 7 (Figure 5A), and the optimum temperatures were between 4 and $25^{\circ} \mathrm{C}$ (Figure 5B). The proteins could not effectively compete with 
A

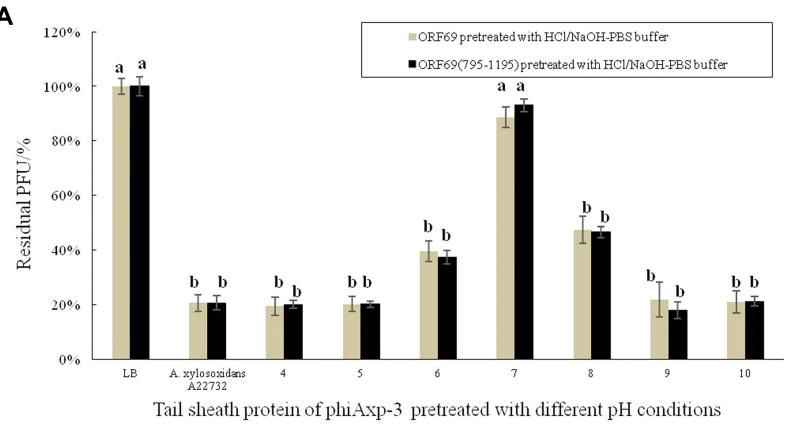

B

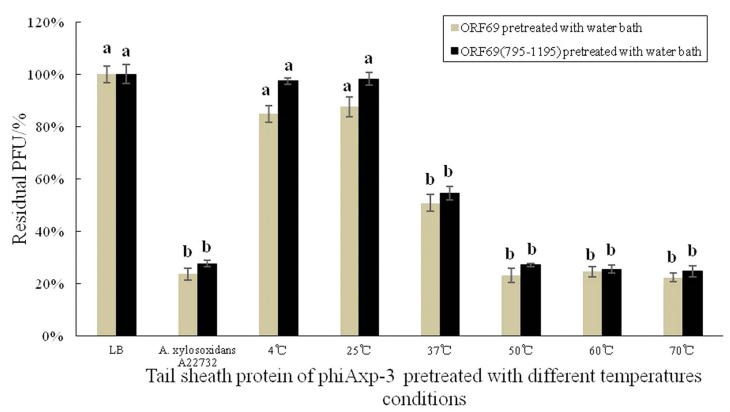

FIGURE 5 | Effects of different pH and temperature pretreatments on the activity of the TSP of phiAxp-3. (A) pH group; (B) temperature group. Numerical values represent the mean of three parallel test results and different letters represent significant differences between data $(P<0.05)$.

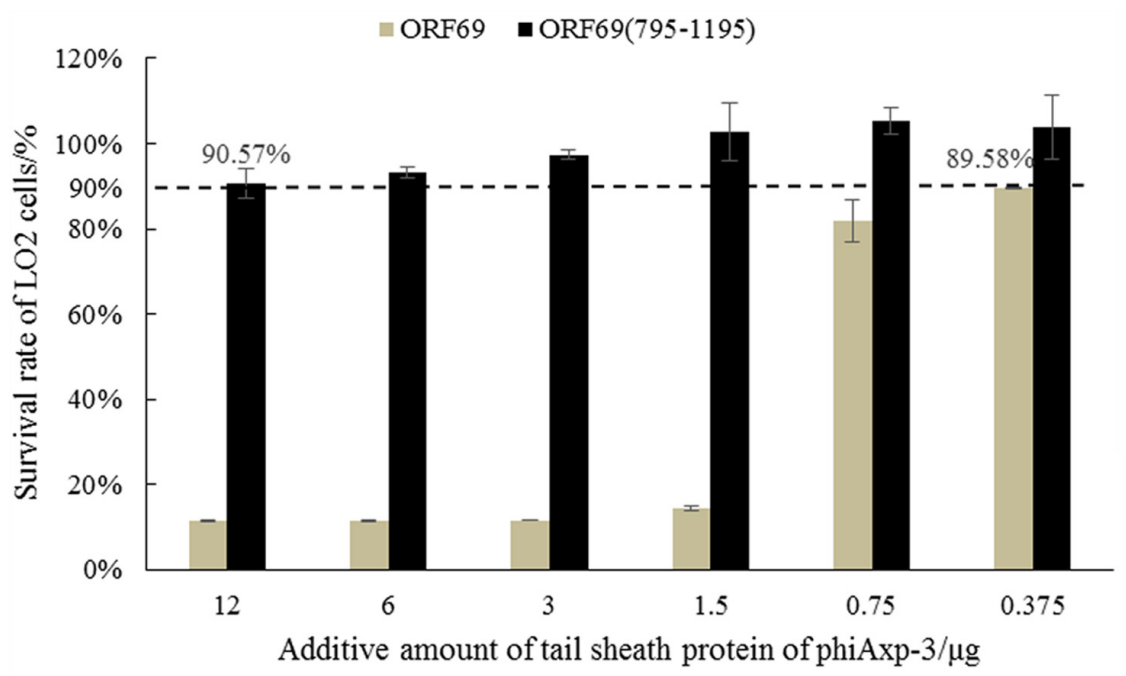

FIGURE 6 | MTT test on survival rates of LO2 cells treated with ORF69 and ORF69(795-1195).

phage to adsorb to host bacteria after treatment in acidic $(\mathrm{pH} 4)$ or basic ( $\mathrm{pH} 10)$ conditions.

\section{Safety Testing of TSP on Cell in Vitro Cell Cultures}

ORF69 and ORF69(795-1195) were tested on the human immortalized normal hepatocyte cell line LO2 in vitro to evaluate their direct toxic effects on cells. Cell viability was assessed by the MTT method. ORF69 was toxic to the cell line when applied with protein doses $>1.5 \mu \mathrm{g} /$ well in cultures, however, no toxic or antiproliferative effects of ORF69(795-1195) were observed (Figure 6). This result indicates that the cytotoxic region of the TSP is independent of residues 795 to 1195.

\section{DISCUSSION}

Phage phiAxp-3 was isolated from hospital wastewater and specifically lysed A. xylosoxidans A22732. phiAxp-3 is an N4-like phage according to morphological study and genome sequencing.
However, this novel phage has a different recognition receptor from N4 phage: N4 phage employs the outer membrane protein $\mathrm{NfrA}$ as the recognition receptor, whereas phiAxp-3 uses LPS (Ma et al., 2016). Gp65 of N4, encoding the TSP, is thought to be the receptor-binding protein. Using the amino acid sequences of TSP of phage N4 as blast query against NCBI database, there is no recognizable sequence similarity between N4 and other reported N4 like phages. This protein was highly unique, the most similar homology searched was the TSP (encoded by ORF69) of phiAxp3 , although they share only $54 \%$ amino acid identity and their binding receptors were totally different (outer membrane protein and LPS, respectively). More than 30 N4-like phages have been reported and sequenced, their most notable feature is the giant RNA polymerase carried in the capsid. The tail proteins (such as tail sheath protein, tail fiber protein, or tail spike protein) responsible for receptor binding showed extensive sequence variability among sequenced N4-like phages. Tail proteins of phages are considered to be a major factor in host specificity. This might be one of the reasons why the hosts of N4-like phages are diverse. A previous study showed that 25 N4-like phage genomes 
share 14 conserved core genes, which do not contain any phage binding genes (Chan et al., 2014), the highly unique binding proteins imply a difference in receptor recognition.

In the present study, recombinant full-length TSP (ORF69) of phiAxp-3 and six variants were co-incubated with the host bacterium. The truncated protein ORF69(795-1195) could directly bind to the host bacteria, with the same function as ORF69 (Figure 3). ELISA confirmed that ORF69(795-1195) could interact directly with A. xylosoxidans A22732 LPS in vitro (Figure 4F). Brzozowska et al. (2015) demonstrated that the T4 bacteriophage tail fiber adhesin for specific LPS recognition is localized near the C-terminus of the protein. In the present study, the essential sequence of phiAxp-3 TSP for specific LPS recognition was also localized near the C-terminus of ORF69. Short proteins recognizing bacterial cells in a specific manner have major implications for better understanding the molecular recognition of cell surfaces and for bacteria detection (Brzozowska et al., 2015).

The characterization of potential therapeutic phages or phage preparations should be undertaken. It is necessary to confirm the stability of the therapeutic phages or phage preparations in different physicochemical conditions (Jończyk et al., 2011). Therefore, in this study, stability studies of ORF69 and ORF69(795-1195) were conducted at different pHs and temperatures. Phages may provide good alternatives to conventional antibiotics, especially for treatment of antibioticresistant pathogenic bacteria (Magiorakos et al., 2012; Deris et al., 2013). Weber-Dạbrowska et al. (2016) propounded that the therapeutic phages or phage preparations were non-toxic, and other researchers support this view in a recent report (JończykMatysiak et al., 2017).

Almost all phages recognize receptors through the phage tail (Chaturongakul and Ounjai, 2014). Therefore, the characteristics, especially the safety, of tail proteins of phages must be determined. Miernikiewicz et al. (2016) demonstrated that the tail protein gp12 of T4 phage is non-toxic. In the present study, the toxicities of ORF69 of phiAxp-3 and ORF69(795-1195) were evaluated using $\mathrm{LO} 2$ cells. The survival rate of $\mathrm{LO} 2$ cells decreased as the dose of ORF69 (0.375-12 $\mu \mathrm{g} /$ well in cultures) increased, indicating that ORF69 may be toxic to the cells (Berridge and Tan, 1993). However, given the same amount of ORF69(795-1195), the survival rate of LO2 cells was $>90 \%$ (Figure 6), indicating that ORF69(795-1195) is non-toxic in this range (doses: $0.375-12 \mu \mathrm{g} /$ well in cultures).

In this study, ORF69(795-1195) was shown to interact with A. xylosoxidans LPS. Recombinant gp12 (the T4 phage tail adhesin) retains the ability to bind LPS, and gp12 was successfully used in an in vivo experiment to counteract LPS-induced inflammation in rice (Miernikiewicz et al., 2016). Kim et al. (2017) demonstrated that a non-toxic LPS binding

\section{REFERENCES}

Berridge, M. V., and Tan, A. S. (1993). Characterization of the cellular reduction of 3-(4,5-dimethylthiazol-2-yl)-2,5-diphenyltetrazolium bromide (MTT): subcellular localization, substrate dependence, and involvement of mitochondrial electron transport in MTT reduction. peptide was an effective anti-inflammatory peptide for the treatment of acute lung injury. Brackett et al. (1997) demonstrated that a synthetic peptide corresponding to amino acid residues 20 through 44 of the neutrophil-derived $37-\mathrm{kDa}$ cationic antimicrobial protein (CAP37 P20-44) can bind lipid A of LPS, which could be useful in attenuating in vivo responses induced during endotoxemia, including sepsis. The emergence of antibiotic-resistant bacteria can cause serious clinical and public health problems (Jung et al., 2017). N4-like phages have been used as therapeutic agent in phage therapy against Pseudomonas aeruginosa infections and have been shown to be safe and effective (Shigehisa et al., 2016). Characterization of the TSP of phage phiAxp-3 might expand our knowledge of using phages as an alternative agent to control multidrug-resistant bacteria. As LPS binding proteins/peptides successfully prevented endotoxininduced responses in vivo, ORF69(795-1195) may be used to develop potential drugs for clinical treatment.

\section{CONCLUSION}

In this study, genes for the TSP of the phiAxp-3 and truncated variants were shown to inhibit phiAxp-3 adsorption onto the host bacterial surface. Experimental results showed no significant difference in residual PFU between the experimental groups [ORF69(595-1395), ORF69(795-1395), and ORF69(795-1195)] and the control (ORF69). Similar experimental results were observed in the interaction between the TSP variants and LPS from the host bacterium. Therefore, proteins with similar functions to full-length TSP (ORF69) were screened and the shortest was identified: ORF69(795-1195). The in vitro cell toxicity of ORF69 and ORF69(795-1195) was tested; ORF69 was highly toxic, but the ORF69(795-1195) was non-toxic when at dose ranges are $0.375-12 \mu \mathrm{g}$. These experimental results can provide references for the application of the TSP of phiAxp-3.

\section{AUTHOR CONTRIBUTIONS}

$\mathrm{ZZ}$ and $\mathrm{XZ}$ designed the research. $\mathrm{ZZ}$ and $\mathrm{JZ}$ performed the research. JY and AJ contributed the new reagents or analytic tools. $\mathrm{XC}$ and RF analyzed the data. XW, HL, WL, and WY provided experimental materials and equipments. ZZ and CT wrote the paper.

\section{FUNDING}

This work received support from National Natural Science Foundation of China (Grant No. 31670174).

Arch. Biochem. Biophys. 303, 474-482. doi: 10.1006/abbi.1993. 1311

Brackett, D. J., Lerner, M. R., Lacquement, M. A., He, R., and Pereira, H. A. (1997). A synthetic lipopolysaccharide-binding peptide based on the neutrophilderived protein CAP37 prevents endotoxin-induced responses in conscious rats. Infect. Immun. 65, 2803-2811. 
Brzozowska, E., Pyra, A., Miśków, M., Górska, S., and Gamian, A. (2015). C-terminal sequence determinants of T4 bacteriophage tail fiber adhesin for specific lipopolysaccharide recognition. Symbiosis 3, 1-5. doi: 10.15226/sojmid/ $3 / 1 / 00130$

Carlson, K. (2005). "Working with bacteriophages: common techniques and methodological approaches," in Bacteriophages: Biology and Applications, eds E. Kutter and A. Sulakvelidze (Boca Raton, FL: CRC Press), 437-494.

Chan, J. Z., Millard, A. D., Mann, N. H., and Schafer, H. (2014). Comparative genomics defines the core genome of the growing N4-like phage genus and identifies N4-like Roseophage specific genes. Front. Microbiol. 5:506. doi: 10.3389/fmicb.2014.00506

Chaturongakul, S., and Ounjai, P. (2014). Phage-host interplay: examples from tailed phages and Gram-negative bacterial pathogens. Front. Microbiol. 5:442. doi: 10.3389/fmicb.2014.00442

Chen, Z., Fang, H., Wang, L., Sun, F., Wang, Y., Yin, Z., et al. (2014). IMP1 encoded by a novel Tn402-like class 1 integron in clinical Achromobacter xylosoxidans, China. Sci. Rep. 4:7212. doi: 10.1038/srep07212

Choi, K. H., Mcpartland, J., Kaganman, I., Bowman, V. D., Rothman-Denes, L. B., and Rossmann, M. G. (2008). Insight into DNA and protein transport in double-stranded DNA viruses: the structure of bacteriophage N4. J. Mol. Biol. 378, 726-736. doi: 10.1016/j.jmb.2008.02.059

Deris, J. B., Kim, M., Zhang, Z., Okano, H., Hermsen, R., Groisman, A., et al. (2013). The innate growth bistability and fitness landscapes of antibiotic-resistant bacteria. Science 342:1237435. doi: 10.1126/science.1237435

Durán, A. E., Muniesa, M., Méndez, X., Valero, F., Lucena, F., and Jofre, J. (2002). Removal and inactivation of indicator bacteriophages in fresh waters. J. Appl. Microbiol. 92, 338-347. doi: 10.1046/j.1365-2672.2002.01536.x

Gerlier, D., and Thomasset, N. (1986). Use of MTT colorimetric assay to measure cell activation. J. Immunol. Methods 94, 57-63. doi: 10.1016/0022-1759(86) 90215-2

Hodyra-stefaniak, K., Miernikiewicz, P., Drapała, J., Drab, M., Jończykmatysiak, E., Lecion, D., et al. (2015). Mammalian Host-Versus-Phage immune response determines phage fate in vivo. Sci. Rep. 5:14802. doi: 10.1038/srep14802

Jończyk, E., Kłak, M., Międzybrodzki, R., and Górski, A. (2011). The influence of external factors on bacteriophages-review. Folia Microbiol. 56, 191-200. doi: 10.1007/s12223-011-0039-8

Jończyk-Matysiak, E., Weber-Dąbrowska, B., Owczarek, B., Międzybrodzki, R., Łusiak-Szelchowska, M., Łodej, N., et al. (2017). Phage-phagocyte interactions and their implications for phage application as therapeutics. Viruses 9:E150. doi: 10.3390/v9060150

Jung, L. S., Ding, T., and Ahn, J. (2017). Evaluation of lytic bacteriophages for control of multidrug-resistant Salmonella typhimurium. Ann. Clin. Microbiol. Antimicrob. 16:66. doi: 10.1186/s12941-017-0237-6

Kiino, D. R., and Rothmandenes, L. B. (1989). Genetic analysis of bacteriophage N4 adsorption. J. Bacteriol. 171, 4595-4602. doi: 10.1128/jb.171.9.4595-4602. 1989

Kiino, D. R., Singer, M. S., and Rothmandenes, L. B. (1993). Two overlapping genes encoding membrane proteins required for bacteriophage $\mathrm{N} 4$ adsorption. J. Bacteriol. 175, 7081-7085. doi: 10.1128/jb.175.21.7081-7085.1993

Kiljunen, S., Datta, N., Dentovskaya, S. V., Anisimov, A. P., Knirel, Y. A., Bengoechea, J. A., et al. (2011). Identification of the lipopolysaccharide core of Yersinia pestis and Yersinia pseudotuberculosis as the receptor for bacteriophage $\varphi$ A1122. J. Bacteriol. 193, 4963-4972. doi: 10.1128/JB.00339-11

Kim, J. Y., Piao, C., Kim, G., Lee, S., Lee, M. S., Jeong, J. H., et al. (2017). Combined delivery of a lipopolysaccharide-binding peptide and the heme oxygenase-1 gene using deoxycholic acid-conjugated polyethylenimine for the treatment of acute lung injury. Macromol. Biosci. 17:1600490. doi: 10.1002/mabi.201600490

Krüger, D. H., and Schroeder, C. (1981). Bacteriophage T3 and bacteriophage T7 virus-host cell interactions. Microbiol. Rev. 45, 9-51.

Lindberg, A. A. (1973). Bacteriophage receptors. Ann. Rev. Microbiol. 27, 205-241. doi: 10.1146/annurev.mi.27.100173.001225

Ma, Y., Li, E., Qi, Z., Li, H., Wei, X., Lin, W., et al. (2016). Isolation and molecular characterisation of Achromobacter phage phiAxp-3, an N4-like bacteriophage. Sci. Rep. 6:24776. doi: 10.1038/srep24776
Magiorakos, A. P., Srinivasan, A., Carey, R. B., Carmeli, Y., Falagas, M. E., Giske, C. G., et al. (2012). Multidrug-resistant, extensively drug-resistant and pandrug-resistant bacteria: an international expert proposal for interim standard definitions for acquired resistance. Clin. Microbiol. Infec. 18, 268-281. doi: 10.1111/j.1469-0691.2011.03570.x

Martínez-Sernández, V., and Ubeira, F. M. (2014). Competitive ELISA for proteinlipopolysaccharide (LPS) binding. Bioprotocol 4:e1298.

Mcpartland, J., and Rothman-Denes, L. B. (2009). The tail sheath of bacteriophage N4 interacts with the Escherichia coli receptor. J. Bacteriol. 191, 525-532. doi: 10.1128/JB.01423-08

Miernikiewicz, P., Kłopot, A., Soluch, R., Szkuta, P., Kęska, W., HodyraStefaniak, K., et al. (2016). T4 phage tail adhesin gp12 counteracts LPS-induced inflammation in vivo. Front. Microbiol. 7:1112. doi: 10.3389/fmicb.2016.01112

Park, K., and Myung, H. (2014). Observation of inflammatory responses in mice orally fed with bacteriophage T7. J. Appl. Microbiol. 117, 627-633. doi: 10.1111/ jam. 12565

Reardon, S. (2017). Modified viruses deliver death to antibiotic-resistant bacteria. Nature 546, 586-587. doi: 10.1038/nature.2017.22173

Richter, Ł., Janczuk-Richter, M., Niedziółka-Jönsson, J., Paczesny, J., and Holyst, R. (2017). Recent advances in bacteriophage-based methods for bacteria detection. Drug Discov. Today 23, 448-455. doi: 10.1016/j.drudis.2017.11.007

Sader, H. S., and Jones, R. N. (2005). Antimicrobial susceptibility of uncommonly isolated non-enteric Gram-negative bacilli. Int. J. Antimicrob. Agents 25, 95-109. doi: 10.1016/j.ijantimicag.2004.10.002

São-José, C., Baptista, C., and Santos, M. A. (2004). Bacillus subtilis operon encoding a membrane receptor for bacteriophage SPP1. J. Bacteriol. 186, 8337-8346. doi: 10.1128/JB.186.24.8337-8346.2004

São-José, C., Lhuillier, S., Lurz, R., Melki, R., Lepault, J., Santos, M. A., et al. (2006). The ectodomain of the viral receptor YueB forms a fiber that triggers ejection of bacteriophage SPP1 DNA. J. Biol. Chem. 281, 11464-11470. doi: 10.1074/jbc.M513625200

Schofield, D. A., and Westwater, C. (2009). Phage-mediated bioluminescent detection of Bacillus anthracis. J. Appl. Microbiol. 107, 1468-1478. doi: 10.1111/ j.1365-2672.2009.04332.x

Shigehisa, R., Uchiyama, J., Kato, S., Takemura-Uchiyama, I., Yamaguchi, K., Miyata, R., et al. (2016). Characterization of Pseudomonas aeruginosa phage KPP21 belonging to family Podoviridae genus N4-like viruses isolated in Japan. Microbiol. Immunol. 60, 64-67. doi: 10.1111/1348-0421.12347

Simin, R., Noor, A., Bahman, T., Mahmood, J. T., Omid, Z., Reza, A., et al. (2011). Extraction, purification and characterization of lipopolysaccharide from Escherichia coli and Salmonella typhi. Avicenna J. Med. Biotechnol. 3, 3-9.

Singh, A., Arya, S. K., Glass, N., Hanifi-Moghaddam, P., Naidoo, R., Szymanski, C. M., et al. (2010). Bacteriophage tailspike proteins as molecular probes for sensitive and selective bacterial detection. Biosens. Bioelectron. 26, 131-138. doi: 10.1016/j.bios.2010.05.024

Soffer, N., Woolston, J., Li, M., Das, C., and Sulakvelidze, A. (2017). Bacteriophage preparation lytic for Shigella significantly reduces Shigella sonnei contamination in various foods. PLoS One 12:e0175256. doi: 10.1371/journal.pone.0175256

Weber-Dąbrowska, B., Jończyk-Matysiak, E., Żaczek, M., Łobocka, M., ŁusiakSzelachowska, M., and Górski, A. (2016). Bacteriophage procurement for therapeutic purposes. Front. Microbiol. 7:1177. doi: 10.3389/fmicb.2016.01177

Westphal, O. (1965). Bacterial lipopolysaccharides: extraction with phenol-water and further applications of the procedure. Methods Carbohydr. Chem. 5, 83-92.

Conflict of Interest Statement: The authors declare that the research was conducted in the absence of any commercial or financial relationships that could be construed as a potential conflict of interest.

Copyright (c) 2018 Zhang, Tian, Zhao, Chen, Wei, Li, Lin, Feng, Jiang, Yang, Yuan and Zhao. This is an open-access article distributed under the terms of the Creative Commons Attribution License (CC BY). The use, distribution or reproduction in other forums is permitted, provided the original author(s) and the copyright owner are credited and that the original publication in this journal is cited, in accordance with accepted academic practice. No use, distribution or reproduction is permitted which does not comply with these terms. 